\title{
SNPs генов IL10, IL4, TGFß1, TNFRSF11B, CRP, EDN1, CYP1A1, NOS3, MMP1 в прогнозе риска развития
}

\section{социально значимых заболеваний}

\author{
Татаркова Е.А.*, Тугуз А.Р., Шумилов Д.С. \\ Адыгейский государственный университет, Майкоп, Россия \\ *warmwild@yandex.ru
}

Ключевые слова: РМЖ, БА, ИБС, TGF 31 , TNFRSF11B, CRP, EDN1, CYP1A1, NOS3, MMP1

Мотивация и цүель: Однонуклеотидные полиморфизмы в регуляторных участках генов влияют на уровень экспрессии, опосредуя специфику биологических эффектов кодируемых протеинов, поэтому типирование аллельных вариантов SNPs генов может быть использовано при определении мишеней для эффективной стратегии лечения заболеваний [1]. В работе исследована ассоциация спектра генов цитокинов (IL10, IL4, TNF $\alpha$ ) и их растворимых рецепторов (TNFRSF11B), ростовых факторов (TGF $\beta 1)$, молекул адгезии, внеклеточных Zn-зависимых эндопептидаз (ММР) и других медиаторов, вовлеченных в патофизиологические механизмы развития ишемической болезни сердца (ИБС), бронхиальной астмы (БА), рака молочной железы (РМЖ) и гестационных осложнений.

Meтоды и алгоритмы: Образцы ДНК неродственных доноров и больных $(n=74)$ с диагнозами БА $(n=13)$, ИБС $(n=10)$, РМЖ $(n=10)$, угрожающим выкидышем в I триместре беременности $(n=8)$ типированы методом ПЦР с электрофоретической детекцией результатов на тест-системах НПФ «Литех» (Москва). Сила ассоциаций оценивалась в значениях показателей отношения шансов (OR), 95 \% доверительного интервала (95\% CI) при $p \leq 0.05$. С помощью программы STRING 10.0 in silico проанализированы белок-белковые взаимодействия.

Pезультаты: У жителей Республики Адыгея с развитием бронхиальной астмы достоверно ассоциирован «нормальный» $\operatorname{Arg} 25$ - полиморфный вариант гена TGF $\beta 1(p \leq 0.05 ; \mathrm{F}=0.038 ; \mathrm{OR}=3.231 ; 95 \% \mathrm{CI}=1.081-9.656)$. Распределение частот аллельных вариантов генов IL-10 (C819T и C592A), CRP (C3872T), IL-4 (C589T), NOS3 (C786T), TNFRSF11B (G1181C), EDN1 (G925T), CYP1A1 (A2454G) и MMP1 (1607insG) у обследованных больных и в контрольной группе достоверно не различаются $(p>0.05)$. Анализ функциональных взаимодействий в STRING database выявил, что 9 белковых продуктов целевых генов участвуют в 24 взаимодействиях, что значительно превышает 3 случайных взаимодействия. Прогнозируемые функциональные партнеры для данной сети включают EDNRA, EDNRB, IL4R, TNFSF11 и AKT1.

Заключение и доступность: Полученные данные позволяют выявить контингент лиц с предрасположенностью к БА и рекомендовать учреждениям здравоохранения разработать комплекс профилактических мероприятий.

\section{Список литературы}

1. Николаева А.М., Бабушкина Н.П., Рябов В.В. Некоторые про- и противовоспалительные цитокины, полиморфные варианты их генов и постинфарктное ремоделирование сердца. Рос. кардиол. журн. 2020;25(10):4007. 